\title{
Desain Kompor Mobile Briket Batubara dan Biomassa Pada Daerah Bencana
}

\author{
Sri Widodo*, Meinarni Thamrin, Sufriadin, Irzal Nur, Asran Ilyas, Monika Sroyer \\ Departemen Teknik Pertambangan, Fakultas Teknik, Universitas Hasanuddin \\ Email: srwd007@yahoo.com*
}

\begin{abstract}
Abstrak
Bencana bajir besar di Provinsi Sulawesi Selatan telah terjadi pada tanggal 22 dan 23 Januari 2019. Peristiwa ini merupakan salah satu bencana yang cukup parah bagi Kota Makassar dan sekitarnya. Kejadian ini mendorong tim pengabdian melakukan pengabdian kepada masyarakat. Kegiatan pengabdian kepada masyarakat UNHASProgram Kemitraan Masyarakat (PPMU-PK-M) telah bermitra dengan salah satu unit usaha (UD Prima Teknik) yang bergerak di bidang pengelasan pagar dan kebutuhan pembesian untuk bangunan. UD Prima Teknik tersebut berlokasi di Kelurahan Antang, Kecamatan Manggala, Kota Makassar. UD Prima Teknik merupakan mitra yang telah membantu tim pengabdian dalam melakukan desain kompor mobile berbahan bakar briket batubara dan biomassa. Kompor yang didesain tersebut telah disosialisasi dan dimanfaatkan untuk kebutuhan masak-memasak dalam memenuhi kebutuhan pangan di daerah-daerah yang mengalami bencana alam. Kompor ini didesain dari besi, kuat, tahan banting, dan mudah dibawa kemana-mana (khususnya ke daerah yang mengalami bencana alam). Bahan bakar yang digunakan pada kompor tersebut berupa briket batubara, kayu atau arang kayu (biomassa). Pemilihan bahan bakar tersebut, selain mudah dibawa dalam perjalanan, juga resiko bahayanya sangat rendah jika dibandingkan dengan kompor gas yang kebanyakan digunakan oleh masyarakat pada saat ini. Bila dalam kondisi terbatasnya bahan bakar briket dan arang kayu, maka kompor ini dapat juga menggunakan bahan bakar kayu yang ada di sekitar wilayah bencana. Dalam kondisi bencana pada suatu daerah, kesulitan yang sering dialami oleh masyarakat adalah sulitnya pasokan/bantuan pangan yang siap saji karena terbatasnya fasilitas dapur (alat untuk memasak).
\end{abstract}

Kata kunci: Kompor mobile; briket batubara; biomassa; arang; bencana.

\begin{abstract}
Big flood disaster in South Sulawesi Province has occurred on January 22 and 23 2019. This event is one of the disasters that is quite severe for the City of Makassar and its surroundings. This incident encouraged the community service team to serve the community. Community service program UNHAS-Community Partnership Program (PPMU-PK-M) has partnered with one of the business units (UD Prima Teknik) which is engaged in fence welding and building maintenance needs. UD Prima Teknik is located in Antang Village, Manggala District, Makassar City. UD Prima Teknik is a partner who has helped the community service team in designing mobile stoves fueled with coal and biomass briquettes. The stove that has been designed has been socialized and used for cooking needs in meeting food needs in disasters areas. This stove is designed from iron, strong, resilient, and easy to carry anywhere (especially to disasters areas). The fuel used on the stove is coal, wood or wood charcoal (biomass) briquettes. The choice of fuel, besides being easy to carry on a trip, is also a very low risk of danger compared to gas stoves that are mostly used by the community at this time. If in conditions of limited fuel briquettes and wood charcoal, then this stove can also use wood fuel that is in the vicinity of the disaster area. In disaster conditions in an area, the difficulty that is often experienced by the community is the difficulty of the supply / assistance of ready-to-eat food because of limited kitchen facilities (tools for cooking).
\end{abstract}

Keywords: mobile stove; coal briquettes; biomass; charcoal; disaster; Prima Teknik

\section{Pendahuluan}

Bencana bajir besar di Provinsi Sulawesi Selatan telah terjadi pada tanggal 22 dan 23 Januari 2019, merupakan salah satu bencana yang cukup parah bagi Kota Makassar dan sekitarnya. Ketinggian air mencapai hingga 2 meter dan menenggelamkan sebagian bangunan dan rumah penduduk. Wilayah yang terkena dampak terparah adalah Kota Makassar, Kabupaten Gowa, 
Kabupaten Maros, Kabupaten Pangkep, dan Kabupaten Jeneponto. Peristiwa ini tentu saja tidak dapat dengan mudah dilupakan begitu saja oleh masyarakat. Di wilayah Kota Makassar, banjir menggenangi beberapa kecamatan, yaitu Kecamatan Manggala, KecamatanTamalanrea, Kecamatan Panakukang dan Kecamatan Biringkanaya. Di wilayah Kabupaten Gowa, Kabupaten Maros dan Kabupaten Pangkep ketinggian air di permukiman penduduk mencapai ketinggian hingga 2 meter. Kejadian ini mendorong tim pengabdian pada masyarakat Fakultas Teknik Universitas Hasanuddin untuk melakukan sesuatu agar dapat meminimalkan dampak yang diderita oleh masyarakat yang menjadi korban banjir. Masalah keperluan bahan makanan di lokasi bencana merupakan masalah yang cukup penting bagi pengungsi korban bajir. Tidak adanya sarana dan prasarana untuk kebutuhan dapur mempersulit ketersediaan bahan makanan yang siap saji bagi pengungsi. Karena itu, kompor mobile berbahan bakar briket batubara, arang, atau kayu bakar sangat tepat digunakan untuk membantu korban di posko-posko pengungsian korban bencana tersebut. Pada kasus seperti ini, tim pengabdian membutuhkan mitra untuk bekerjasa sama. Mitra yang dibutuhkan adalah mitra yang dapat mendesain dan memproduksi kompor untuk melakukan kegiatan ini. Salah satu mitra tersebut adalah UD Prima Teknik yang terletak di Kelurahan Antang, Kecamatan Manggala. Sulitnya memperoleh pasokan gas sebagai bahan bakar untuk kepentingan dapur di posko bencana dapat diantisipasi dengan penggunaan kompor berbahan bakar briket batubara, kaya bakar, atau arang ini. Selain untuk keperluan di daerah bencana, kompor ini juga memiliki peluang untuk dijadikan komoditas bisnis dalam memenuhi kebutuhan masakmemasak sehari-hari bagi masyarakat yang tidak memiliki kompor gas. Untuk itu tim pengabdian mencoba bermitra dengan salah satu unit usaha pengelasan besi untuk memanfaatkan peluang tersebut. Selain masalah teknis, tim pengusul pengabdian juga telah melakukan bimbingan kepada mitra terkait manajemen dan strategi pemasaran produk yang dihasilkan.

Pada saat ini manajemen usaha mitra masih dilakukan dengan cara manual dan menerima pesanan pekerjaan dari order yang dipesan oleh pelanggan yang sifatnya musiman atau kebetulan. Persoalan yang dihadapi oleh unit usaha ini masih terkendalanya produksi yang tidak tetap dan kurangnya perencanaan yang berkesinambungan dalam memperoleh pesanan (order) pekerjaan. Untuk meningkatkan kinerja unit usaha dipandang perlu untuk melakukan diversifikasi jasa yang dikerjakan. Salah satunya adalah dengan memproduksi kompor mobile yang dapat dijual/disuplai ke daerah-daerah bencana yang membutuhkan kompor tersebut. Kekosongan pekerjaan pada saat tidak ada kegiatan utama, maka membuat dan menjual kompor ini bisa menjadi solusi untuk meningkatkan produktivitas unit usaha.

\section{Latar Belakang Teori}

Banjir adalah peristiwa meluapnya aliran sungai akibat air melebihi kapasitas tampungan sungai sehingga meluap dan menggenangi dataran atau daerah yang lebih rendah di sekitarnya (Yulaelawati, 2008). Dalam siklus hidrologi dapat disimpulkan bahwa volume air yang mengalir pada permukaan bumi dominan ditentukan oleh tingkat curah hujan, dan tingkat peresapan air ke dalam tanah. Aliran Permukaan merupakan curah hujan - (resapan ke dalam tanah + penguapan ke udara).

Kondisi pada saat terjadinya banjir di Provinsi Sulawesi Selatan (Kota Makassar dan sekitarnya) diperlihatkan pada Gambar 1. Kejadian ini mendorong tim pengabdian pada masyarakat Universitas Hasanuddin untuk melakukan sesuatu agar dapat meminimalkan dampak yang diderita oleh masyarakat yang menjadi korban banjir. Gambar 2 memperlihatkan kondisi korban bencana yang berada di posko-posko pengungsian dengan sarana dan prasarana yang sangat terbatas (terutama kebutuhan bahan pangan). 
Kompor mobile berbahan bakar briket, kayu bakar, dan arang sangat tepat digunakan untuk membantu korban di posko-posko pengungsian korban bencana untuk mendukung kebutuhan suplai pangan (kegiatan masak-memasak).

Permasalahan yang sering dihadapi pada posko pengungsian bencana alam adalah masalah konsumsi (makan dan minum) bagi korban bencana. Karena itu tim pengabdian pada masyarakat Unhas bekerja sama dengan mitra akan membuat kompor mobile berbahan bakar briket batubara atau arang dan kayu bakar dengan model seperti yang diperlihatkan pada Gambar 3. Kompor seperti yang diperlihatkan pada Gambar 3 didesain dari besi agar mudah dibawa kemana-mana dan tahan banting (tidak pecah atau rusak). Kompor ini dapat digunakan untuk semua jenis masak-memasak, baik merebus, menggoreng maupun memanggang (membakar).

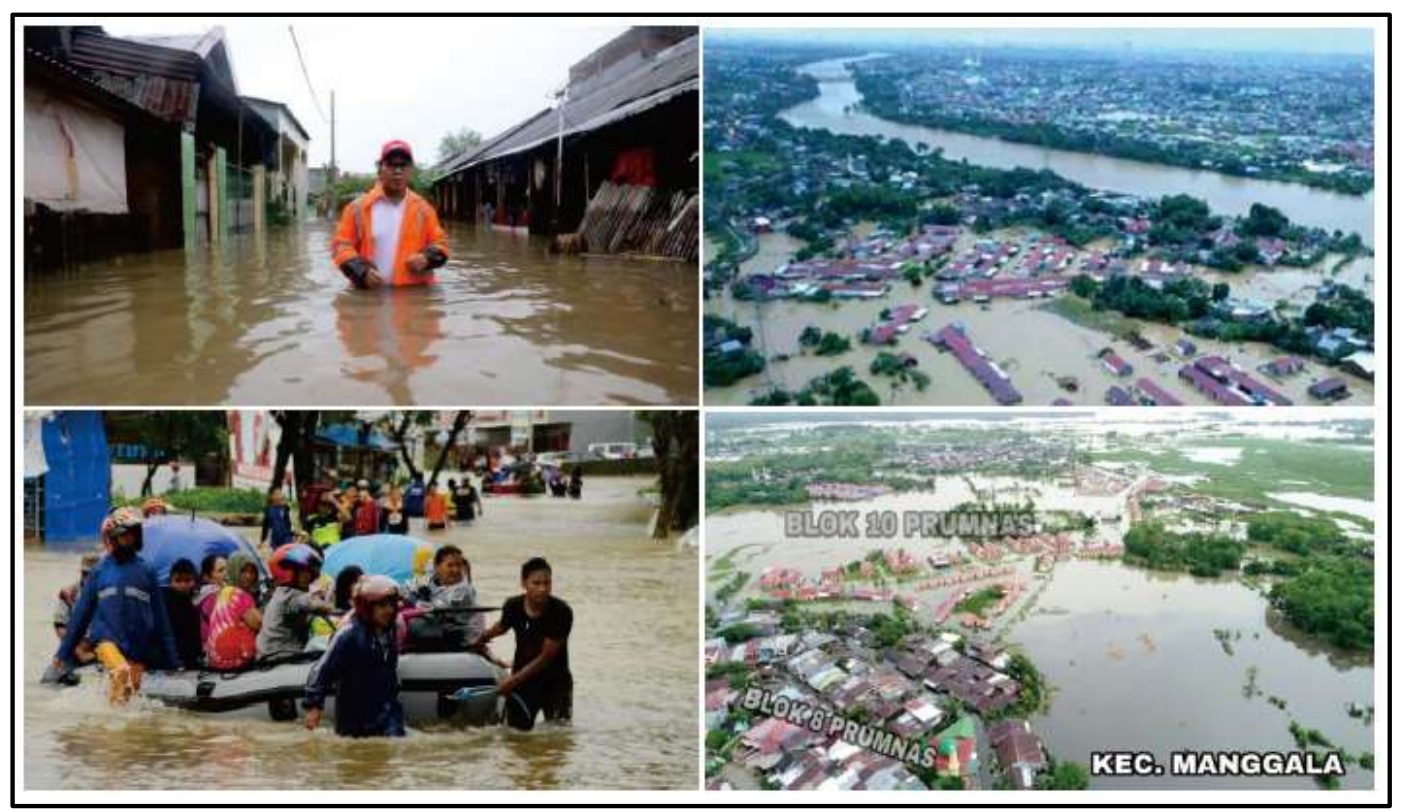

Gambar 1. Kondisi di beberapa wilayah pada saat terjadi banjir di Provinsi Sulawesi Selatan

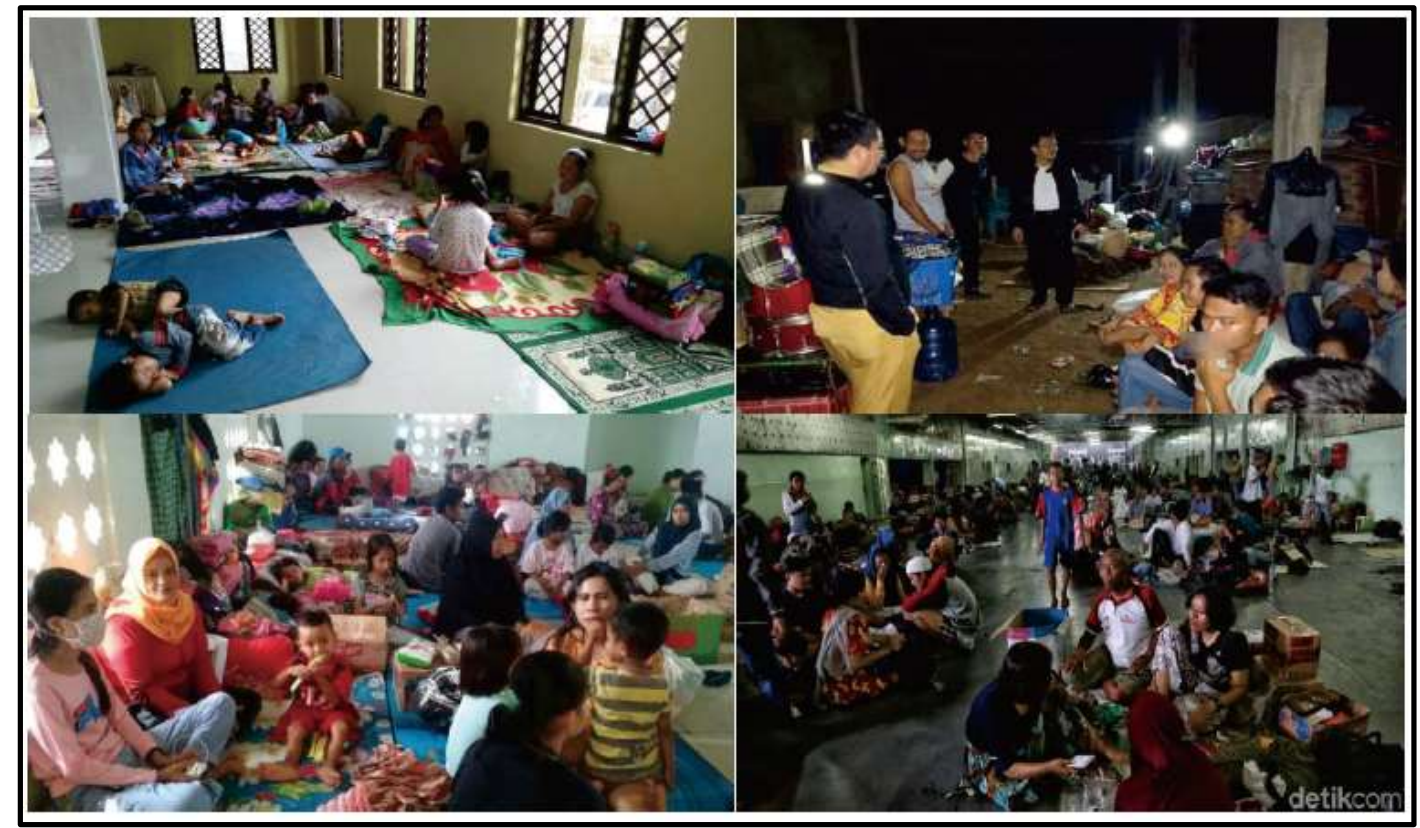

Gambar 2. Kondisi korban bencana banjir di posko-posko pengungsian 
Di bagian tengah kompor diberikan kisi-kisi (bentuk ayakan atau besi menjaring) berupa besi yang berfungsi sebagai wadah (tempat) untuk briket batubara, kayu bakar atau arang. Abu sisa pembakaran briket batubara atau arang akan terkonsentrasi ke bagian bawah kompor dan abunya dapat tertampung (terkumpul) di bagian bawah kompor. Pada bagian bawah kompor diberi lubang bukaan udara primer agar suplai oksigen dapat berlangsung dengan baik pada saat tahap penyalaan kompor. Apabila briket atau arang telah benar-benar menyala, maka pintu lubang primer dapat segera ditutup agar briket atau arang dapat memberikan panyalaan (panas) yang maksimal pada saat memasak, merebus, ataupun menggoreng. Bahan bakar yang digunakan pada kompor ini berupa briket batubara atau arang seperti yang diperlihatkan pada Gambar 4. Briket batubara, kayu bakar dan arang kayu telah banyak digunakan diberbagai negara sebagai sumber energi dan bahan bakar, diantaranya beberapa negara yang terdapat di Afrika (Njenga, 2017; Njenga, dkk.., 2015; Onekon dan Kipchirchir, 2016a; Onekon dan Kipchirchir, 2016b; UN-Habitat Somalia Programme, 2014). Selanjutnya untuk mitra sendiri, kegiatan pengabdian ini akan memberikan dampak secara bisnis dan ekonomi apabila kompor tersebut diproduksi dalam jumlah yang banyak dan berkualitas.

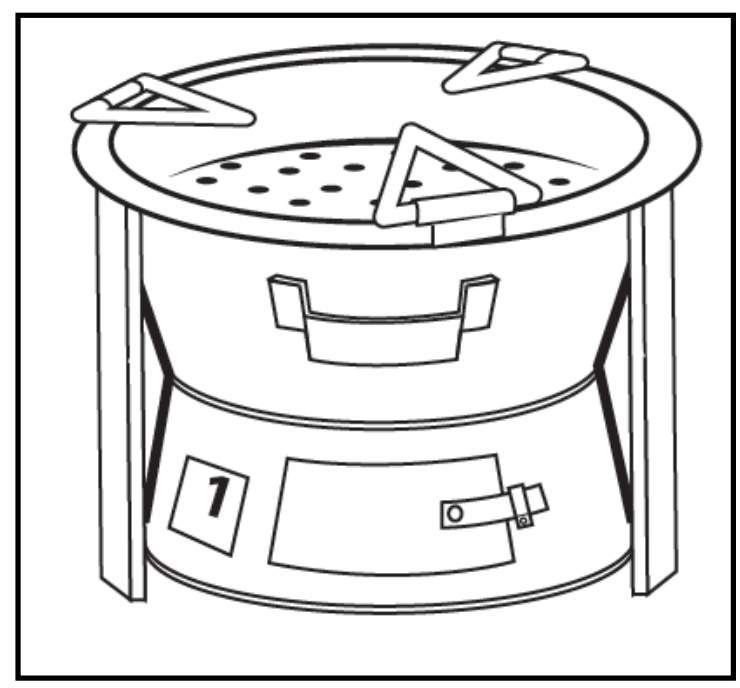

Gambar 3. Prototipe kompor mobile yang didesain dalam program pengabdian PPMU-PKM.
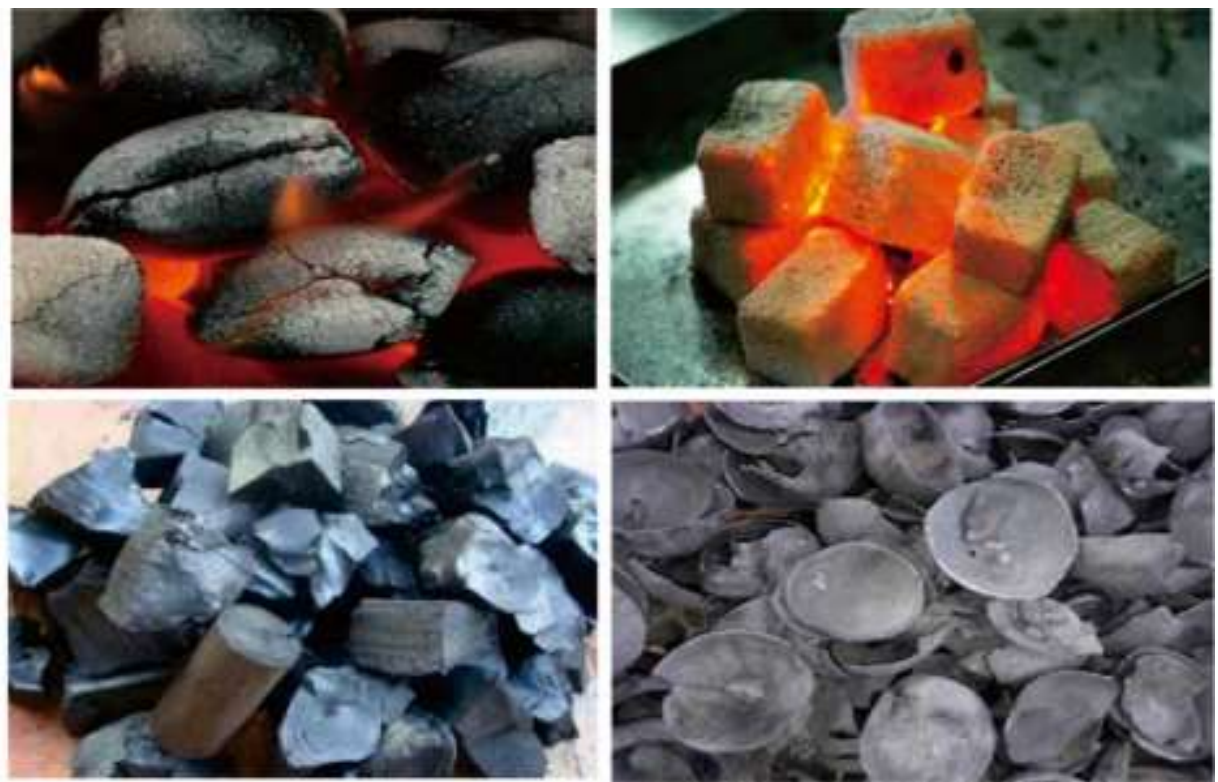

Gambar 4. Briket batubara atau arang yang digunakan pada kompor mobile 


\section{Metode}

Metode pelaksanaan kegiatan pengabdian PPMU-PK-M dilaksanakan dengan langkahlangkah sebagai berikut:

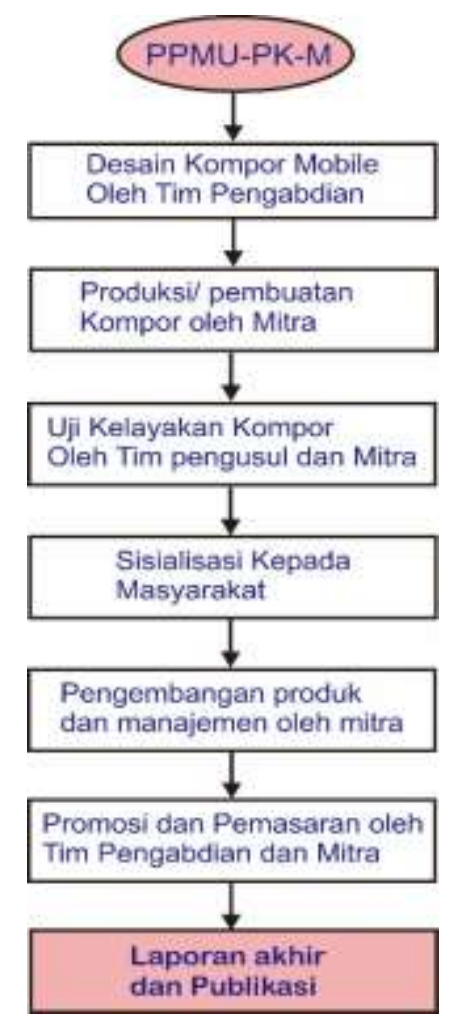

Gambar 5. Bagan alir metode pelakasanaan kegiatan PPMU-PK-M

a) Kompor mobile didesain oleh tim pengusul pelaksana pengabdian.

b) Produksi kompor mobile akan dilakukan oleh mitra sesuai permintaan (order) dari tim pengabdian PPMU-PK-M.

c) Bila kompor mobile telah selesai diproduksi (dibuat) maka uji kelayakan dilakukan oleh tim pengusul pengabdian bersama-sama dengan mitra.

d) Bila kompor telah memenuhi uji kelayakan, maka sosialisasi penggunaan kompor akan dilakukan pada masyarakat di Kelurahan Katimbang Kecamatan Biringkanaya (salah satu lokasi yang terdampak banjir cukup parah).

e) Kompor yang telah layak pakai akan dipromosikan kepada masyarakat agar dapat digunakan tidak hanya di daerah bencana, tetapi juga dapat digunakan untuk kebutuhan masak-memasak sehari-hari dalam memenuhi kebutuhan pangan di keluarga masingmaisng.

f) Pihak mitra dapat mengembangkan lebih lanjut untuk pemasaran kompor dan manajemen peluang bisnis produk pengabdian ini.

g) Tim pengabdian akan membantu terkait dengan permasalahan pemasaran.

h) Menyusun laporan akhir pengabdian dan publikasi hasil pengabdian pada jurnal ilmiah nasional "Jurnal TEPAT".

Metode pelaksanaan kegiatan pengabdian PPMU-PK-M oleh Departemen Teknik Pertambangan secara detail diperlihatkan pada Gambar 5. 


\section{Hasil dan Diskusi}

Kompor hasil desain antara tim pengabdian dan mitra diperlihatkan pada Gambar 6 . Berdasarkan hasil desain, kompor tersebut dapat dimanfaatkan untuk keperluan memasak, menggoreng, dan membakar. Bahan bakar yang digunakan dapat berupa sampah kayu, briket batubara maupun bahan biomassa lainnya.

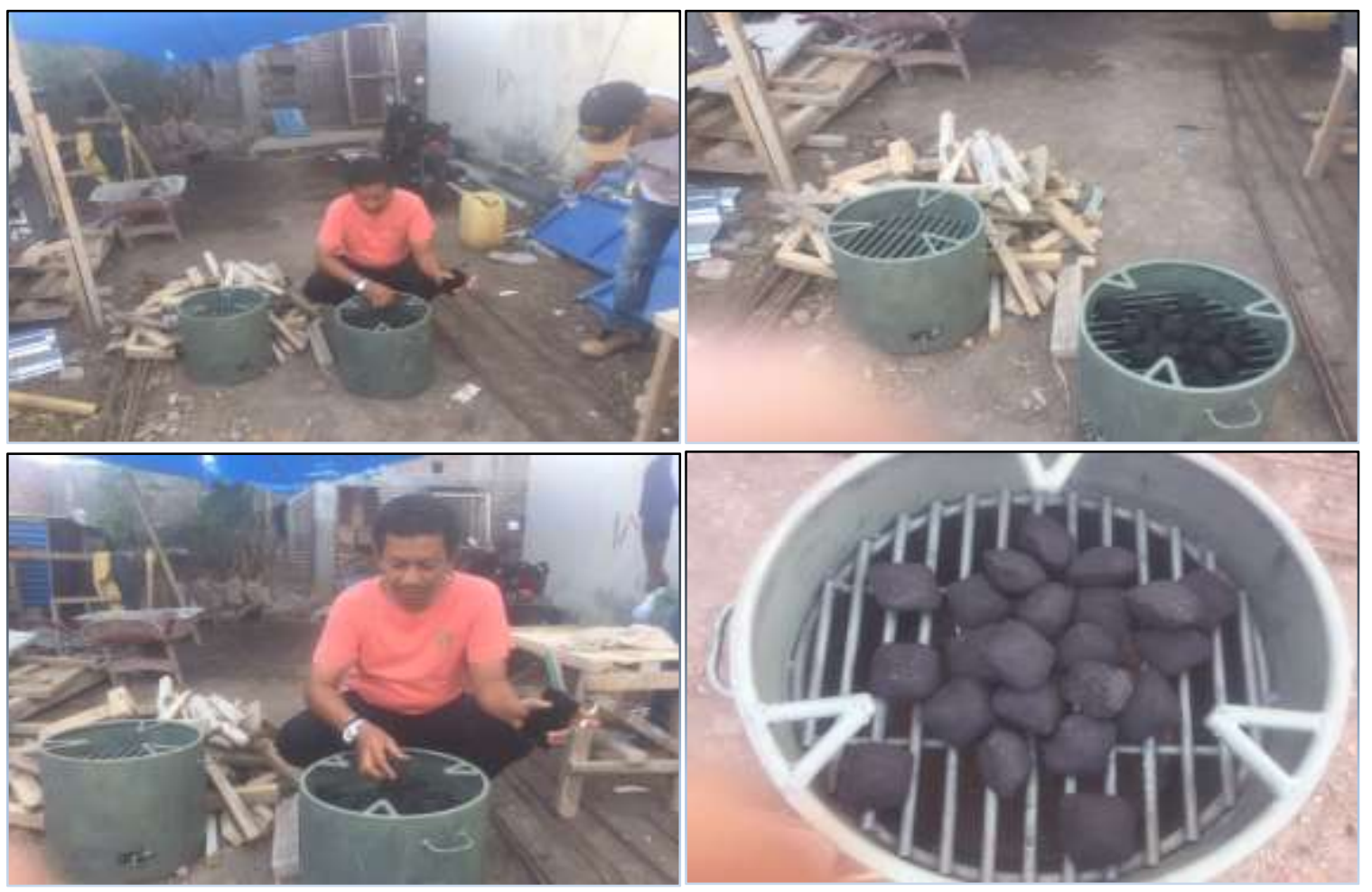

Gambar 6. Kompor mobile berbahan bakar briket batubara, arang, dan kayu bakar.

Uji penyalaan pada kompor menggunakan kayu bakar dan briket batubara diperlihatkan pada Gambar 7. Hasil uji memperlihatkan proses pembakaran kayu dan briket batubara pada kompor dapat dilaksanakan dengan baik dan efektif. Proses penyalaan berlangsung dengan cepat dan kompornya dapat segera digunakan untuk memasak makanan, air, maupun kebutuhan lainnya.

Gambar 8 memperlihatkan Kegiatan sosialisasi penggunaan kompor hasil desain tim pengabdian bersama mitra dan masyarakat. Sosialisasi penggunaan kompor ini dilaksanakan di Kelurahan Katimbang Kecamatan Biringkanaya Kota Makassar. Kegiatan sosialisasi dilaksanakan bersama mitra dan masyarakat di daerah pengabdian pada masyarakat. Kegiatan ini disambut dengan baik dan dapat memberikan manfaat kepada masyarakat yang ada di sekitar wilayah bencana. Selain sosialisasi, kegiatan ini diharapkan dapat memberikan peluang kepada mitra dikemudian hari apabila ada masyarakat yang membutuhkan kompor seperti yang telah didesain. 


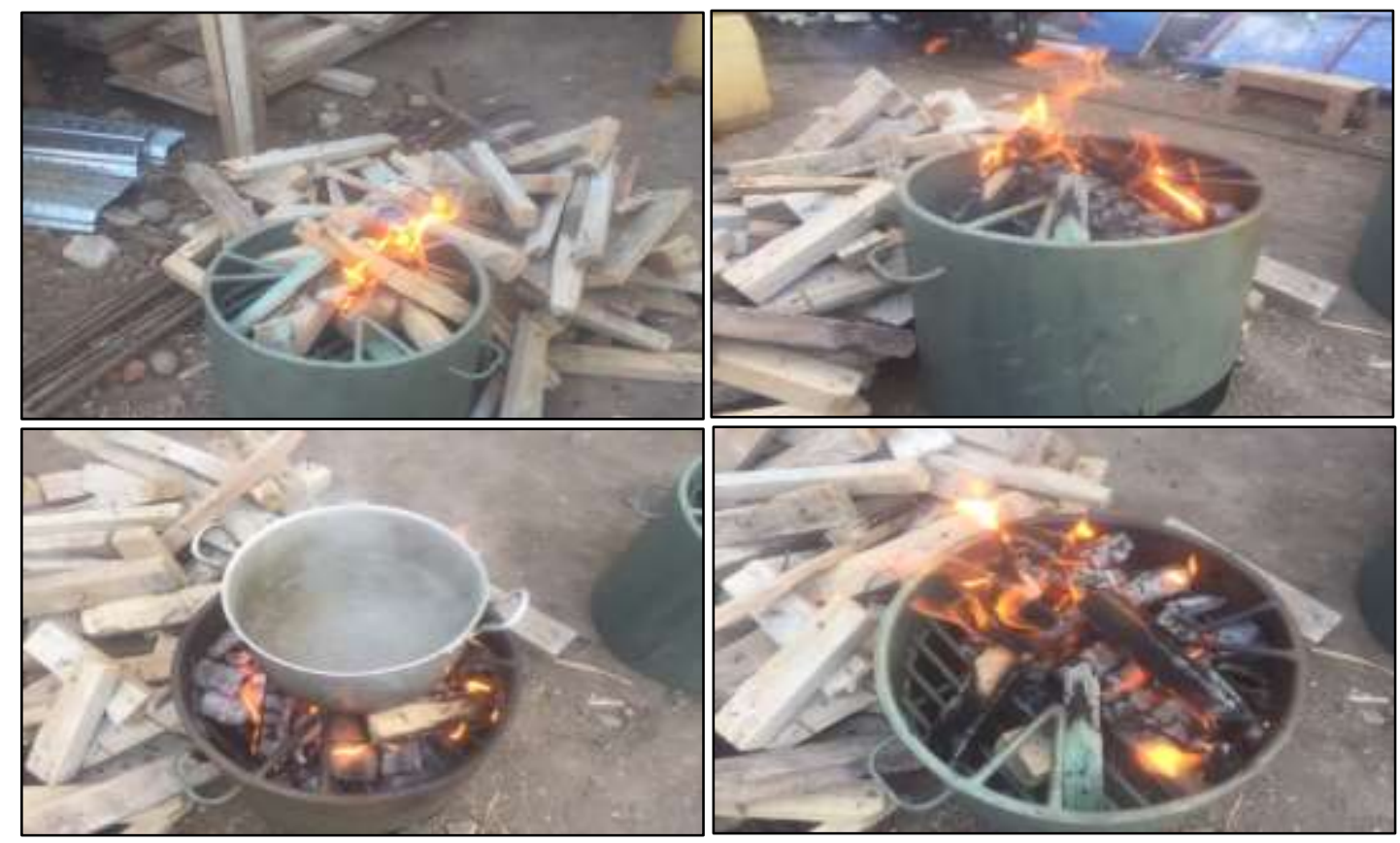

Gambar 7 Uji coba pembakaran pada kompor mobile oleh tim pengabdian bersama mitra.

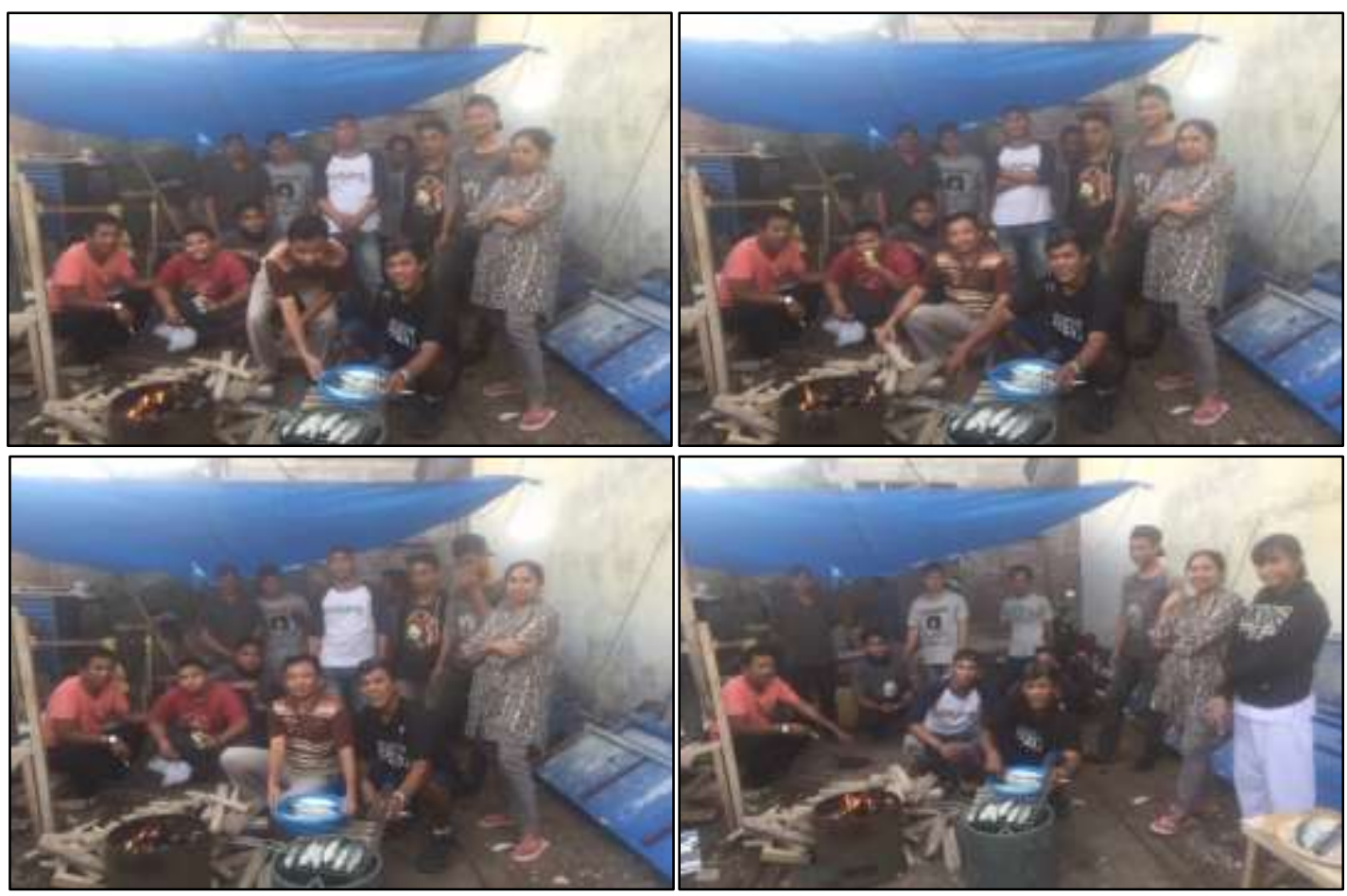

Gambar 8. Kegiatan sosialisasi penggunaan kompor mobile bersama masyarakat.

Gambar 9 memperlihatkan kegiatan pemanggangan (pembakaran) ikan menggunakan kompor kegiatan pengabdian kepada masyarakat bersama-sama dengan masyarakat. Pada Gambar 9 terlihat bahwa proses pembakaran ikan berlangsung dengan efektif tanpa ada kendala apapun dalam kegiatan pembakaran. Hasilnya memperlihatkan proses pembakaran yang sempurna dan proses pematangan ikan berjalan dengan baik. 


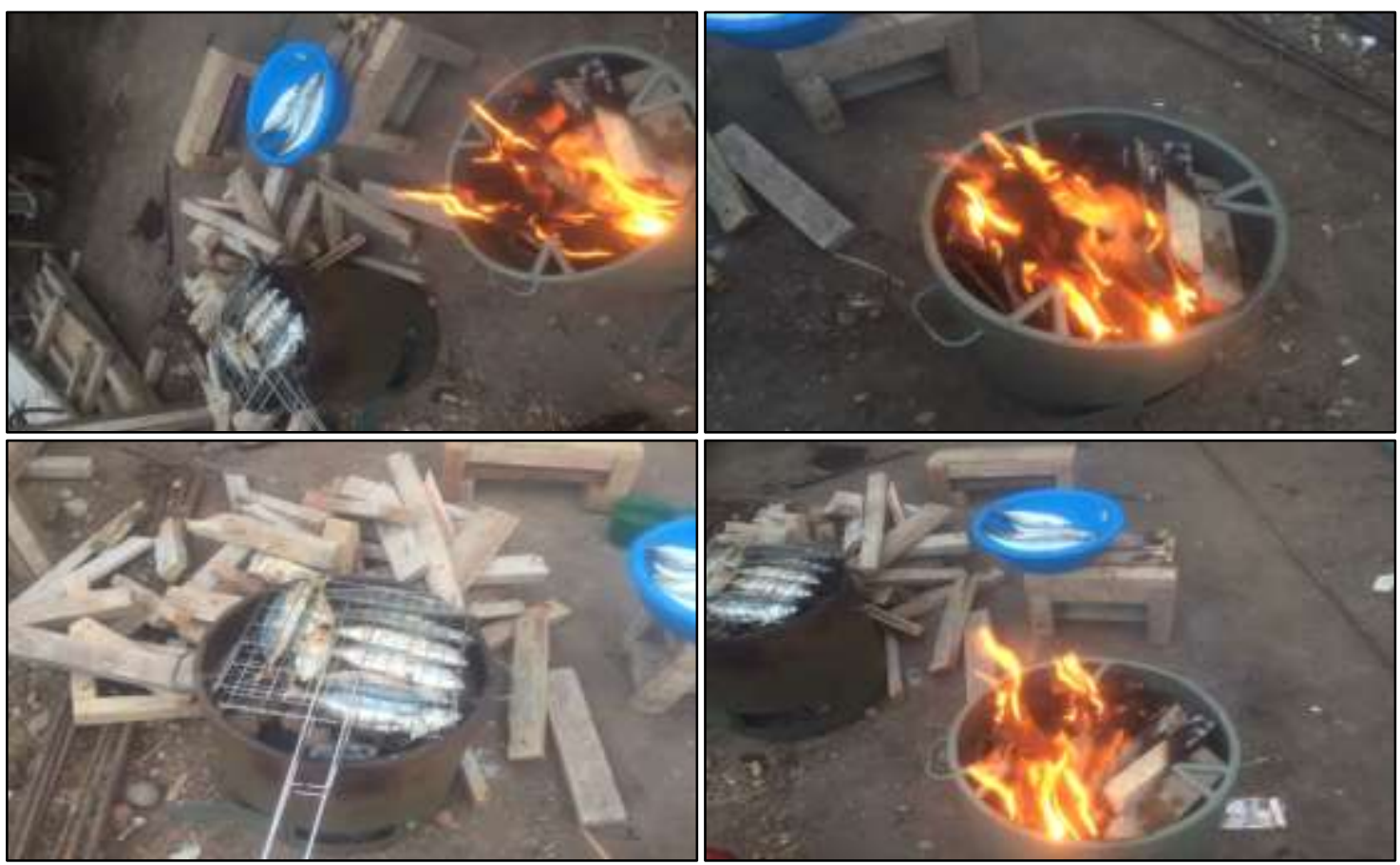

Gambar 9. Pemanfaatan kompor untuk pemanggangan ikan dan keperluan lainnya.

\section{Kesimpulan}

Berdasarkan hasil kegiatan pengabdian kepada masyarakat bersama mitra dapat disimpulkan bahwa proses desain kompor berbahan bakar kayu bakar, arang, atau briket batubara memberikan manfaat yang baik di daerah pengabdian. Hasil uji coba pembarakan dan kegiatan sosialisasi pemanfaatan kompor menunjukkan respon yang positif bagi masyarakat di Kelurahan Katimbang, Kecamatan Biringkanaya, Kota Makassar. Kompor-kompor tersebut dapat dimanfaatkan untuk proses memasak, menggoreng, maupun memanggang atau membakar bahan makanan. Proses penyalaan kompor dapat dilakukan dengan mudah. Karakteristik kompor yang didesain ini adalah kompor sangat kuat, dapat dibawa ke manamana, tidak mudah pecah, tahan banting, dan terbuat dari besi plat yang berkualitas. Kompor ini sangat prospek untuk dapat dikembangkan oleh mitra dalam rangka pemanfaatannya bagi masyarakat dan dapat menjadi peluang bisnis bagi mitra di masa yang akan datang.

\section{Ucapan Terima Kasih}

Penulis mengucapkan terima kasih kepada Fakultas Teknik Universitas Hasanuddin atas dukungan biaya dalam kegiatan pengabdian melalui program PPMU-PK-M tahun 2019. Terima kasih disampaikan kepada mitra pengabdian bapak Haji Basir (UD Prima Teknik ) yang telah mendukung kegiatan pengabdian ini.

\section{Daftar Pustaka}

Njenga, M., 2017. Evaluating fuel briquette technolgies and their implications on greenhouse gases and livelihoods in Kenya. A thesis of doctor of philosophy.

Njenga, M., Karanja, N., Karlsonn, H., Jamnadass, R., Liyama, M., Kithinji, J., Sundberg, C. 2015. Additional cooking fuel supply and reduced global warming potential from recycling charcoal dust into charcoal briquette in Kenya. Journal of Cleaner Production 81, $81-88$. 
Onekon, W. A., Kipchirchir, K. O., 2016a. Assessing the effect of charcoal production and use on the transition to a green economy in Kenya. Tropical and Subtropical Agroecosystems, 19, $327-335$.

Onekon, W. A., Kipchirchir, K. O., 2016b. Assessment of Consumer Awareness on Environmental Effects of Charcoal Production and Use in Nairobi City, Kenya. International Journal of Science and Research (IJSR), ISSN (Online): 5, 2319-7064.

UN-Habitat Somalia Programme, 2014. Charboal briquette production - A Practical Training Manual. pp. 1 - 21.

Yulaelawati, E. 2008. Mencerdasi Bencana. Jakarta: Gramedia. 